Saudi Journal of Business and Management Studies Abbreviated Key Title: Saudi J Bus Manag Stud ISSN 2415-6663 (Print) |ISSN 2415-6671 (Online) Scholars Middle East Publishers, Dubai, United Arab Emirates Journal homepage: http://scholarsmepub.com/sjbms/

Original Research Article

\title{
Investigate the Impact of Customer Relationship Management and Organizational Learning Capabilities on the Financial Performance of Producers of Herbal Products
}

\author{
Dr. Behrooz Hassanpour ${ }^{1 *}$, Hamed Rostamian ${ }^{2}$ \\ ${ }^{1}$ Assistant Professor of Economic, Social and Extension Research Department, Kohgiluyeh and Boyerahmad Agricultural and Natural Resources \\ Research and Education Center, AREEO, Yasouj, Iran \\ ${ }^{2}$ Graduate Student in Governmental Management-Financial, Islamic Azad University, Yasouj Branch, Iran
}

DOI: $10.36348 /$ sjbms.2019.v04i09.007 $\quad$ Received: 29.04.2019| Accepted: 11.05.2019| Published:23.09.2019

*Corresponding author: Behrooz Hassanpour

Abstract

The present study seeks to examine the impact of customer relationship management (CRM) and organizational learning capabilities (OLC) on the financial performance of the company that produces products of Cinere plant origin. To measure organizational learning capabilities and measure customer relationship management used of the standard questionnaires formats. The research questionnaire was distributed among 90 individuals of the statistical community that was all the directors and employees of Cinere Company and were randomly studied. The research method was descriptive correlational. In order to answer the questions and investigate the research hypotheses with smart-PLS terminals, the method of studying structural equations and path analysis using partial least squares method (PLS) was used. The results showed that organizational learning capabilities and its dimensions have a positive and significant effect on customer relationship management and company financial performance. On the other hand, the research results do not confirm the significant effect of customer relationship management and its dimensions on financial performance of the company.

Keywords: Customer Relationship Management (CRM), Cinere Company, Financial Performance, Organizational Learning Capabilities (OLC).

Copyright @ 2019: This is an open-access article distributed under the terms of the Creative Commons Attribution license which permits unrestricted use, distribution, and reproduction in any medium for non-commercial use (NonCommercial, or CC-BY-NC) provided the original author and source are credited.

\section{INTRODUCTION}

Today, organizations operate in a dynamic and complex environment, has increased the Competition between organizations and, the life cycle of products has declined, and decline the life span of the organizations. In many cases, manufacturers produce the same quality goods and this is the customer who makes the purchase decision [1]. Customer relationship management is an organizational process that integrates employees, organizations, business processes, market orientation, and information and communication technology in order to build and maintain customer relationships. And allows companies to seek for content analysis, that access to customer data and store and use of them [2-4]. Customer relationship management uses information technology as a coordinated tool for maximizing customer value and maintaining relationship [5]. However, in addition to the technical tools companies to support and promote company learning, need to build infrastructures. Which can be a very important factor in creating and maintaining relationships with customers [6]. These relationships mainly relate to the creation acquisition merge of knowledge that improves the ability of the company to interact with customers, develop resources, and adapt new and adaptive capabilities to actively learn to serve customers and enhance the company's performance [7]. Despite recognized, that provide a unique economic value by customers for companies and that there was a 
significant increase in corporate customer relationship management investment [8], But there had little effort to highlight organizational results from a customercentric approach [9]. Although some university researchers have specifically focused on a positive relationship between customer relationship management and it's performance, but some studies have suggested breach results about the implementation of customer relationship management and company performance processes. These contradictory results shows that empirical research is limited to investigating the impact of customer relationship management on organizational performance [10]. Recent literature has emphasized that the development of an enterprise dynamic process is able to run the creation, conservation, and integration of knowledge to use resources and capabilities to assist successful management. And also causes contact with the customer [11]. The main goal of customer relationship management is to identify valuable customer. Therefore, the organizational learning capabilities of customer relationship management Collaborates to collect and integrate information on customers, to predict new customer needs and provide customer value through production of design and service that requires a strong understanding of tacit knowledge. In this case, companies need infrastructures that can deployed technology resources into customer relationship management that deployed to develop a production process [10]. Based on the prevailing premise in this study Strategic organizational conditions are needed to acquire, disseminate, and interpret knowledge And with more clarity, cause dynamic organizational learning capabilities [1].

Organizational learning is the most important way to enhance long-term performance and in the near future, only an organization can had superiority claim to be able to take advantage of the capabilities, commitment, and capacity to teach individuals at all levels of the organization. In organizational learning, members, will gain experience for the future by recognizing and correcting errors and cause of make themes, as well as correct the mistakes and prepare to deal with changes and possible incidents [12].

Organizational learning capabilities (OLC) that is a condition for the realization of organizational learning in an organization - includes four factors of management commitment for organizational learning, having a systemic vision of the organization's goals transfer and integrations of knowledge, open space and test space. The management commitment for learning means that management understands the importance of learning. And create a culture in the organization that account the acquisition and creation of knowledge as a core value in the organization. A systemic vision means that different individuals, sectors, and organizational areas have a clear view of the organization's goals and they know how to contribute to the development of these goals. Open space makes it possible to test new ideas inside or outside the organization and this experiment is essential for creative learning. Transfer of knowledge is essentially created through conversation and interaction between people. Dialogue and Negotiation Individuals and Working Groups and their Meetings are Ideal gatherings for the sharing of ideas for transferring of knowledge [13]. Many industries in the country have been stagnating as a consequence of the problems that have occurred in the majority of manufacturing and service sectors in the country. Cinere Company is among these industries. The company that works in the field of cosmetic products has succeeded in developing its domestic and even foreign market. Unfortunately, during the recent years, the country's economic downturn, on the one hand, and the sanctions imposed on Iran, on the other hand, have had a negative impact on Cinere sales and turnover. On the one hand, Cinere enters some of his original sources from Germany, it exports some of its products to the Gulf countries and European countries this, as well as reducing the purchasing power in the domestic market, has had a negative impact on Cinere financial performance. Given this issue and considering the impact of customer orientation and organizational learning on improving organizational performance, financial performance, which is one of the main dimensions of the performance of each organization, leads to the improvement of this problem in Cinere Co. The research results and the experiences of successful companies confirm this. Despite the financial problems of Cinere, customaries and focus on financial needs of customers have led to the maintenance and development of customers. And this plays a major role in increasing the company's sales and improving its financial performance. On the other hand, organizational learning leads to lower costs for the organization through tests and errors, increasing the speed of work along with improving the quality, strengthening the knowledge of corporate governance, and thus improving the financial performance of the green manufacturing company.

According to the presented topics, this study seeks to investigate that whether organizational learning and customer relationship management capabilities are effective on financial performance of the company. It should be noted that, as far as we know, no research in Iran has empirically tested the relationship between organizational learning capabilities, customer relationship management and company financial performance. Hence the aim of this study is to fill this gap through a concept that is under development.

\section{Theoretical Literature and Research Background Customer Relation Management}

The need for the development of information technology and especially the global Internet web and e-commerce has created an opportunity to improve customer relationship with previous facilities in today's competitive markets. The last goal is to turn these communications and interactions into greater 
profitability through increase duplicate purchases and lower costs for customer acquisition. In fact, this evolution of customer relationship management is a new marketing theory. Customer relationship management or, in other words, customer-oriented management is a set of customer-driven processes and strategies that is supported by a specific software to enhance customer loyalty and, ultimately, increase profitability of the company. One of the requirements of that is attract a suitable customer, create a value proposition, institutionalize the best practices, motivate employees, and educate customers [14].

Customer relationship management (CRM) is a complex application that extracts customer data which is obtained through customer contact points. And while discover the characteristics of key customers and predicted their purchasing patterns, creates a single, comprehensive view of the customer. Today, marketing managers have determined that customer relationship management focuses on building long-term, longlasting relationships with the customer that create valuesfor both the customer and the company. Customer relationship management is more than mere technology [15].

Customer relationship management requires a steady effort to main process engineering from the customer's perspective, by participating in it and receiving feedback. In a product-centric approach, the goal is to find a customer for products using marketing efforts. But a customer-centric approach, aimed at developing products and services to suit customer needs [16]. On the other hand, implementing an enterprise technology, such as customer relationship management, requires a change in organizational culture. However, technology and business processes are both necessary for the success of customer relationship management. But the personnel of the organization are the cornerstones of relations with consumers. The successful implementation of customer relationship management requires attention to the various dimensions of management and staff of the organization the commitment to excellent management is one of the key factors for the success of customer relationship projects. A customer-centric model need to share data at the organization's level that requires a paradigm fundamental change in the in the culture of sharing knowledge and information [16].

\section{Organizational Learning Capabilities Learning}

Experts have provided many definitions for learning. Robbins [17] describes learning as follows "Learning is any kind of behavior change that occurs as a result of experience. One of the definitions accepted by a number of scholars of learning is the definition given in the Britannica Encyclopedia. That is as follows:
Learning is the relatively stable change that occurs in the potential behavior of the individual through excercising and training [18].

\section{Learner Organization}

A learning organization is an organization that takes over and managing all intellectual power, knowledge and experience of the organization to make changes and continuous improvement for development [19].

Learner organization features:

- Encourage people at all levels to learn their work regularly;

- Possessing systems and processes for learning and publishing in the organization;

- Valuing for learning.

\section{Organizational Learning}

Today, with regard to the issue of globalization, organizations must change their structure to survive in line with changes in the perimeter of the environment. Or equip themselves with tools to help them cope with global changes. One of the most important aspects of these tools is the creation and institutionalization of organizational learning [20]. The concept of organizational learning dates back to 1900 When Taylor put forward the transfer of learning from one person to another to increase efficiency and improve the organization [13]. Nadi et al., Quoting Dibla and colleagues, have defined organizational learning as the capacity or processes within an organization to maintain or improve performance based on experience. This process involves the acquisition of knowledge (the creation or development of skills, insights and interpretations), knowledge sharing (the dissemination of knowledge ridden by the individual to others) and the use of knowledge (Integrating knowledge, so it be absorbed, be widely available, be generalized to new conditions) [21].

Organizations are also a collection of human individuals and groups that are subject to enormous environmental changes and over time, they learn about their actions and activities. In other words, organizations should be like other people with learning ability. For this reason, the subject of organizational learning is attended by new organizational and management theories. It can be concluded that one of the great challenges in various levels of management is the increase of organizational learning capability [22]. Organizational learning is: Increasing organizational capacity for doing things and so this learning practice in the organization happens when: Firstly, the managers and key elements of the organization have aware of the phenomena of their organization and Secondly, this recognition will be reflected in their behavior and performance and the organization's set [23]. In fact, organizational learning is the development and use of 
new knowledge in a way that can change the behavior of employees.

\section{Organizational Learning Capabilities}

Organizational learning capabilities represent a set of obvious competencies that, as a Special knowledge use technological and process skills, distinguishes the organization from its competitors and makes it able to adapt to its environment. In his view, learning capabilities for the organization are like fuel As the gasoline moves the car, learning capabilities prepare organization for predict internal and external changes and Answers to them [24]. Organizational learning capability develops the ability of individuals to access new information and transforms this information into knowledge. And such an operation is critical to organizational activities, because organizations can maintain their competitive advantage.

Hult \& Ferrell [25] the organization's ability to encourage, invent, and innovate, facilitate and maintain continuous learning is called organizational learning capability and the four factors that reflect the learning ability are as follows:

- Systemic: Mention important organizational factors who widely think about organizational variables. Systemic organization focused to organize and meaning each organizational phenomenon from the point of view of the organization as a whole. Systematic is vital and critical that can lead an organization for adapt to learning [26].

- The organizational environment for learning: Indicates value and encourages learning in the organization. The organizational environment for learning is one of the key components in organizational culture. That specifies the beliefs accepted by the organization and the static behavior patterns among the actors in the organization. Therefore, the organizational environment for learning comes from the daily learning behaviors of individuals and groups that in turn affects organizational learning, adaptability, process crises to maintain organizational success and survive in a turbulent environment [27].

- Acquiring and applying knowledge: It refers to the amount of organization's expertise in acquiring and acquiring the knowledge necessary to improve and transform into processes, structures, and innovations. Acquisition and used of knowledge are two sub-processes in organizational learning. Knowledge acquisition has a significant rotating effect that increases the knowledge of an organization so it facilitates organizational learning and obviously learning is a collective nature that can facilitate more learning. Applying knowledge emphasizes that acquired knowledge can create new abilities.

- Sharing and disseminating information: reveals that the information is accessible to the organization. Sharing information will help employees that achieve new knowledge and thus better estimate the needs of the organization [28]. States that: Without sharing and disseminating information and knowledge in an organization, cannot created synergies and it's important for any organization to increase its competency [29].

\section{Background and Conceptual Model of Research Background of Internal Investigation}

Hassan-Gholipour et al., [30] have reviewed the model of customer relationship management process in private commercial banks. They claimed that one of the reasons for failure to implement customer relationship management is the lack of tools and criteria for measuring and assessing customer relationships. Mohsenian et al., [31] conducted a research on the impact of customer relationship management on satisfaction through the role of the interface innovation. (Case study: Municipality of Mashhad). The results showed that only the relationship between customer relationship management and the Innovation is significant and confirmed. Other aspects of the relationship include: the relationship between communication management and being satisfied. The relationship between innovation and being satisfied. And the intermediary of innovation between customer relationship management and customer being satisfied are not approved. Pashazadeh conducted a research entitled "The effect of leadership transformational style on organizational learning capabilities" in 2014, considering the role of the mediator of organized. (a) The transformational leadership style has a direct and significant positive effect on organizational intelligence and organizational learning capability. Organizational intelligence has a direct positive and significant effect on organizational learning capability. (c) Organizational intelligence is a limited and intermediate interface between the transformational leadership style and organizational learning capability. (d) The transformational leadership style, directly and indirectly, through organizational intelligence, has a significant effect on organizational learning capability. Montazer Someae Sarayi et al., [32] studied the status of organizational learning capabilities and barriers and facilitators at the University of social welfare and rehabilitation sciences. The results indicate that the level of learning in the studied university was higher than the average level.

Zablah et al., [33] have emphasized both the input and the output of the system to conceptualize the customer relationship assessment tool. Based on this conceptual framework, customer relationship management can be implemented by linking the knowledge management process to customer intelligence (internal process) and the implementation of the interactive management process that controls customer relationships (external process). Linfgreen [34] proposed a ten-element tool for evaluating customer relationship management that is divided into 
three general subsets: Strategic elements such as customer and brand strategy Infrastructure elements like culture and manpower Process elements like the process of managing relationships. Soch \& Sandburg [35] conducted a study aimed at identifying the effect of customer relationship management on the company's financial performance in India. The study identified four related customer relationship structures that included sensitivity to customer needs, communications, intermediaries, and the company's internal environment. Ullahzid and Almudimigh [36] have provided a framework for a balanced scorecard of communication with the client to evaluate these systems in Saudi banks and improve customer satisfaction and loyalty. In this research, the research indicators and their measurement are also described. Nonetheless, the model is a result-oriented model, because other models that use the balanced scorecard it has not comprehensive approach and process. Bolivar and Ramos [37] have a research titled Distinctive qualities of technology and Organizational Learning: The Impact of it on organizational Innovation in order to Improving Corporate Performance. The results of the empirical analysis, based on examples from 21 Spanish technology companies, show that First, the senior management's support is effective on technology skills, the distinctive technological and organizational competencies of learning. Senior Manager's support for technology skills, and the distinctive technological and organizational competence of effective learning. Secondly, the distinctive competence of technology and organizational learning affects organizational performance directly and indirectly through organizational innovation. Abdulalem et al., [38] have conducted research on the impact of customer relationship management (CRM) on organizational performance dimensions. This study was a quantitative study that was carried out in relation to 152 Malaysian hotel managers from 3 to 5 stars. Data was collected and regression analysis was performed. The results of this study indicated that all dimensions of customer relationship management (customer orientation, customer relationship management knowledge management customer relationship management based on technology) are positive and have a significant impact on the performance of the hotel at different times. However, customer relationship management technology has a significant relationship with the learning and performance of the hotel. Akgun et al., [39] have conducted a research called the
Communication Bridge between organizational learning capability and corporate performance through customer relationship management. The results indicated that considering the sharing of the results of knowledge and its integration, it seems to be mentioned as an important factor, which increases the success of CRM through all members of the organization in a customer-centric approach. Kalmuka and Acar [40] have conducted the research that called the role of intermediary organizational learning capability in the relationship between innovation and corporate performance: they have a conceptual framework. The results showed that innovation has a positive effect on yield. The positive impact of innovation on corporate performance can be increased as a result of the role of an intermediary in organizational learning. Ghalenooiea and Sarvestania [41] have done research on human factors in customer relationship management. The survey community were private bank employees in Shiraz and Data were collected using a questionnaire. The findings of this research show that human factors have a positive impact on customer relationship management. Meanwhile, factors such as displaying, and understanding are more effective.

\section{Conceptual Model of Research}

From previous researches, it can be seen that with respect to organizational learning and sharing of the results of knowledge and its integration, it can be named as an important factor that increased CRM's success through all members of the organization in a customer-centric approach. And to be formed an organizational structure, where in resources are dedicated to customer satisfaction and value creation. It is obvious that customer relationship management is an important factor in the company's performance in the presence of senior management, which is shaped and supported than learning. There is a general view of the integrated effort towards organizational goals, the transparency of culture, and the sharing of knowledge among members of the organization. Which can lead to improved company performance through customer relationship management But what's new in this research is whether improving organizational learning can lead to improved customer relationship management and In this way, improve the financial performance of the company, that always indicates the strength and ability of the company and the most important indicator for measuring the company's performance? 


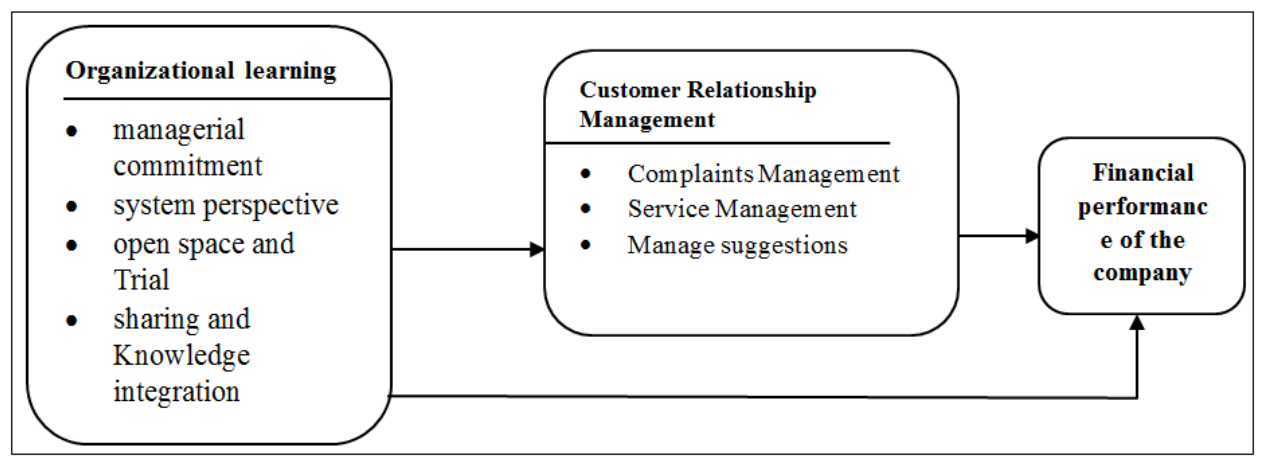

Fig-1: Conceptual Model of Research (The Impact of Organizational Learning Capabilities and Customer Relationship Management on Corporate Financial Performance)

Source: (Okgobin et al., 2014)

According to the conceptual model of the research, the research hypotheses are as follows.

- Organizational learning capabilities have an impact on corporate financial performance.

- Organizational learning capabilities affect customer relationship management.

- Customer relationship management affects the company's financial performance

- Organizational learning through customer relationship management affects corporate financial performance.

\section{RESEARCH METHODOLOGY}

The method of this research in terms of purpose is applied and in terms of data collection method, it is descriptive and correlation type. In fact, this research is a quantitative research that Investigates and analyzes hypotheses by dealing with the correlation of variables. Information used in this research is divided into two categories.

The first set of information is related to theoretical foundations and research literature, which is provided through studying various articles and dissertations on the Internet and various publications through library studies. The second category is the second data of statistical data obtained from the analysis of the standard questionnaires that given to sample individuals.

The assumption of normal society was rejected using the Kolmogorov-Smirnov test. Due to the low sample size, the partial least squares (PLS) method was used (less than 200) to process the model and assumptions. This method is suitable for samples less than 200 and abnormal. In order to investigate the research hypotheses, structural modeling was used with partial least squares method and PLS software. The normal PLS is a variance-based approach, which requires fewer conditions compared to similar techniques of structural equation like Lisrel and Amos Lijnder, Paul and Enriel, 2009. The main advantage is that this type of modeling needs less samples than lasers Wickson and Watson, 2001. It is also proposed as a powerful method, in conditions that the number of samples and measurement items is limited and the distribution of variables can be indefinite [42]. PLS prototyping is done in two steps. In the first step, the measurement model should be checked through validity and reliability analysis and confirmatory factor analysis. In the second step, the structural model is examined by estimating the path between the variables and determining the fit indexes of the model [43].

\section{Statistical Population, Sample Size and Data Collection Tool}

The statistical population of this research is 160 executives and experts of Cinere Co. The company, called Living nature that was founded in 1376 with the aim of producing quality products for Skin and hair care with Plant origin. The company markets its products under the brand name of Cinere. Cochran test was used for determine the samples size, Based on this formula, the sample number was 90 . The sampling is performed randomly. After reviewing the theoretical foundations and models presented and using the dimensions and indicators extracted, that formed the conceptual framework of the research. The standard questionnaire of the research was obtained and after obtaining the experts Opinions Dear Professors. A final questionnaire was compiled for Collect field data. Likert Five Optional Spectrum Was drafted that is one of the most suited scales in research. Information about measuring the research data was collected by three valid questionnaires. The organizational learning questionnaire had 16 questions and were designed and written by Augun et al., [39]. The customer relationship management questionnaire had 11 questions and respondents were asked to express their views on the subject. The questionnaire was also designed and written by Akgun et al., [39]. The company's financial performance questionnaire also includes 6 questions and is designed and written by Quranfleh et al., 2014. To determine the face and content validity of the questionnaire, the views of the university professors and the managers and experts of Cinere Co. who were familiar with the subject were used. According to the findings, validity of the questionnaire was confirmed. This issue was also assessed by two convergent and divergent validity criteria, which is specific to structural 
equation modeling. The reliability of the questionnaire pre-test showed that Organizational learning capabilities are 0.82, Customer Relationship Management was 0.81, corporate financial performance was 0.92 , and Cronbach's Alpha rate of the whole questionnaire was 0.797. Which showed that the Cronbach's Alphabet questionnaire is appropriate.

\section{Data Analysis and Presentation of Findings}

The one-dimensional indices are the first factor to be taken into consideration in the evaluation of reflexive models. That means that any index in the aggregate of indexes, with a large load factor, is to be loaded into only one dimension or Hidden variable. For this reason, acceptable loads are introduced. Above $60 \%$. As shown in the second figure, the numbers or coefficients are divided into two categories. The first set of measurement equations is the relationships between hidden variables (oval) and obvious variables (rectangular). These equations are called Factor loads. The second group is the structural equation that are the relationships between the hidden and hidden variables, and are used to test the hypotheses. These coefficients are probably path coefficients. According to the model estimating coefficients, we can estimate the factor loads and the path coefficients.

Based on factor loads, the index that has the most factor load has a larger share in measuring the corresponding variable. And the index with smaller coefficients plays a smaller role in measuring the corresponding structure. The results of the factor loads are given in Fig-2.

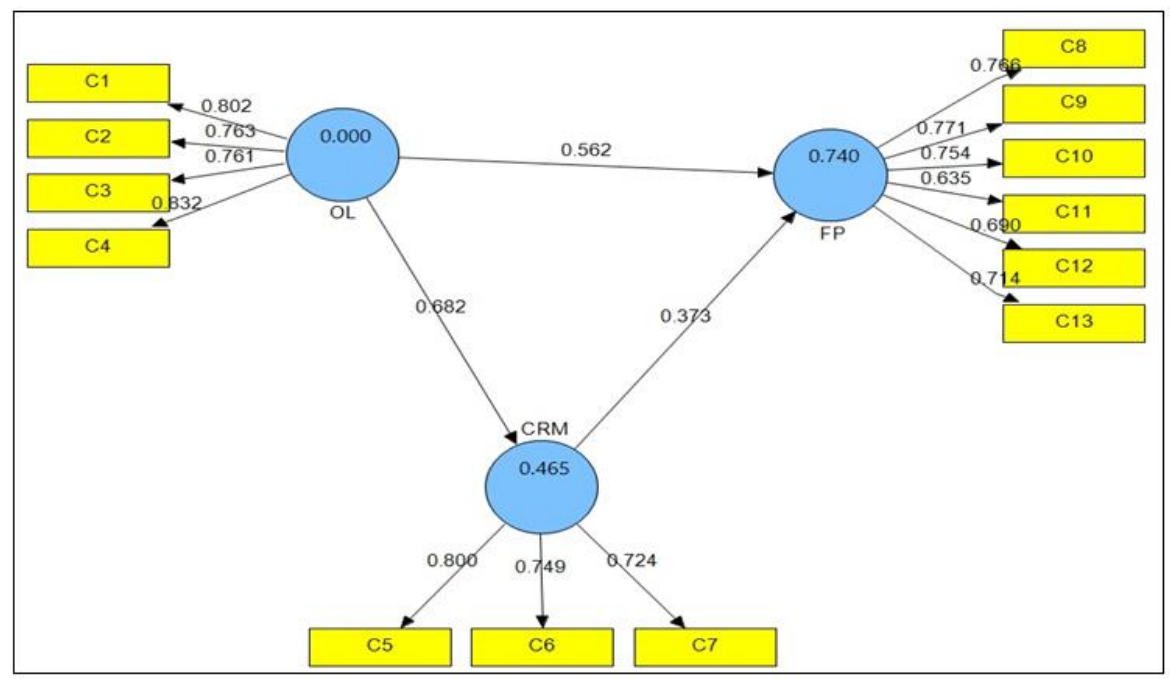

Fig-2: Output of the software, the tested model of research (Path coefficients and factor loads)

Since all values are greater than 0.6, that indicative the suitability of the model indicators. In the validity and reliability of the models are shown using PLS in Table-1.

Table-1: Validity and model reliability

\begin{tabular}{|l|l|l|l|l|}
\hline Model Structures & $\begin{array}{l}\text { Convergent } \\
\text { Validity } \\
\text { (AVE) }\end{array}$ & $\begin{array}{l}\text { Divergent } \\
\text { Validity }\end{array}$ & $\begin{array}{l}\text { Cronbach's } \\
\text { Alpha }\end{array}$ & $\begin{array}{l}\text { Cr Composite } \\
\text { Reliability }\end{array}$ \\
\hline Organizational learning & 0.6244 & 0.7901 & 0.8468 & 0.8443 \\
\hline $\begin{array}{l}\text { Customer relationship } \\
\text { management }\end{array}$ & 0.5753 & 0.7584 & 0.8115 & 0.8658 \\
\hline $\begin{array}{l}\text { Corporate financial } \\
\text { performance }\end{array}$ & 0.5230 & 0.7231 & 0.8667 & 0.8374 \\
\hline
\end{tabular}

\section{Second stage: Structural model and hypothesis test based on the (PLS) method}

A structural pattern test that is related to the examination the hypothesis of research and the effect of hidden variables on each other. To confirm the research hypotheses, the smart PLS bootstrapping command was used which indicates that the output yields the coefficients of the product of the coefficients (Figure-
$3)$. When $t$ values were more than +1.96 and less than 1.96 indicate the Significance of the parameter and subsequently the confirmation of research hypotheses (Esposito, Vienna, Chien, Hensler and Wang, 2010). As shown in two charts, the $t$ coefficients are larger than 1.96 between all research structures, so all assumptions are confirmed. Table- 2 shows the results of all the research hypotheses. 
Table-2: The results of all the research hypotheses

\begin{tabular}{|c|c|c|c|c|}
\hline Hypotheses & $\begin{array}{l}\text { Standardized path } \\
\text { coefficient }(\beta)\end{array}$ & T Statistics & Significance & $\begin{array}{l}\text { Accept or Reject } \\
\text { the hypothesis }\end{array}$ \\
\hline $\begin{array}{l}\text { Organizational learning } \\
\text { capability } \rightarrow \text { financial performance of } \\
\text { the company }\end{array}$ & 0.562 & 8.272 & $\mathrm{Sig}<0.5$ & Accept \\
\hline $\begin{array}{lr}\begin{array}{l}\text { Organizational } \\
\text { capabilities } \rightarrow \text { customer } \\
\text { management }\end{array} & \text { relationship } \\
& \end{array}$ & 0.682 & 13.136 & Sig $<0.05$ & Accept \\
\hline $\begin{array}{l}\text { Customer } \\
\text { Management } \rightarrow \text { Corporate } \\
\text { Performance }\end{array}$ & 0.373 & 0.957 & Sig $>0.05$ & Reject \\
\hline $\begin{array}{l}\text { Organizational learning capabilities } \\
\text { indirectly through the Mediator } \\
\text { Variable of customer relationship } \\
\text { management } \rightarrow \text { financial performance } \\
\text { of the company }\end{array}$ & 0.682 and 0.373 & $\begin{array}{ll}0.957 & \text { and } \\
13.136 & \end{array}$ & Sig $>0.05$ & Reject \\
\hline
\end{tabular}

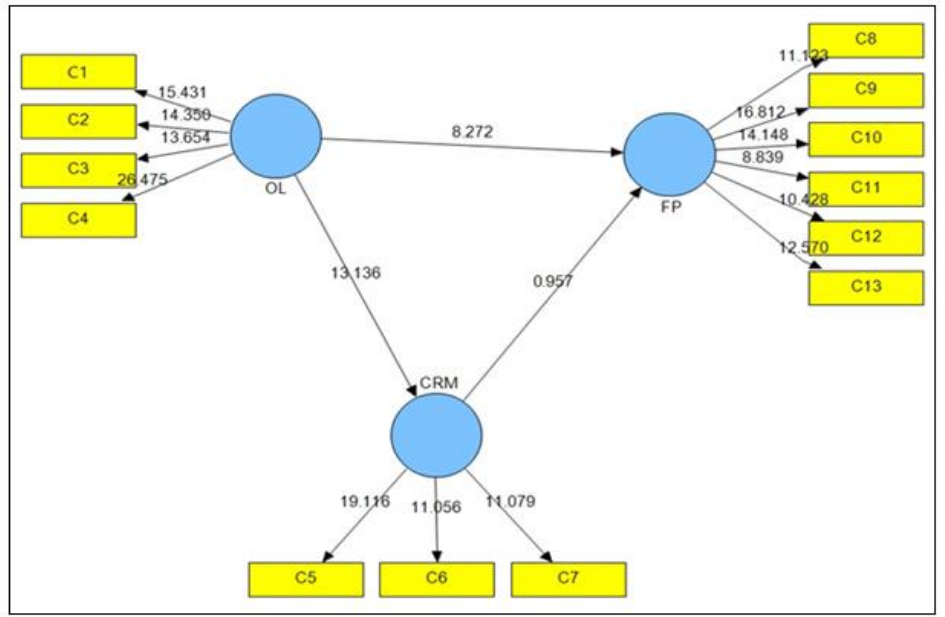

Fig-3: Output of software t coefficients related to research hypotheses

\section{CONCLUSION AND RECOMMENDATIONS}

The purpose of this research is an empirical test that examines the capabilities of corporate learning and customer relationship management on Cinere Co. financial performance. Keramati et al., [1] suggested that the impact of a comprehensive customer relationship management approach on corporate performance has significant implications for participating in organizational complementary processes in which all dimensions of customer relationship management are very helpful to the company's operations. But what has been achieved in this research is that Customer relationship management has no significant effect on financial performance of the company. And through it and its indicators, the company's financial performance cannot be improved. The very important result of this study is that organizational learning capabilities are a key factor in improving customer relationship management and corporate financial performance. The results demonstrates that customer relationship management Execute interacts with organizational learning capabilities for strategic, tactical, and operational effort to build long-term, and mutually beneficial relationships with customers in the performance. This research also describes our knowledge of customer relationship management in two ways. First, it emphasized on the essence of the insight acquired from the organizational learning and customer relationship management capabilities to success in customer knowledge and it processing. And achieved new approaches and maintained long-term, mutually beneficial relationships with customers. Second, there is evidence that organizational learning capabilities, the culture of the common environment in the organization, the use of common language and the adoption of a shared vision among employees to support customer relationship management, was adopted. The results confirm the impact of all aspects of the organizational learning capabilities of customer relationship management. By sharing and integrating knowledge results, it seems to be called an important factor that increases the success of customer relationship management through all members of the organization in a customer-centric approach. And it takes shape an organizational structure in which resources are allocated according to customer satisfaction and value creation. It is obvious that supporting corporate learning by senior management is 
an important factor in improving company financial performance. Therefore, a general view of it and integrated effort towards organizational goals, Transparency of culture and sharing knowledge dignity among members of the organization can lead to improved corporate financial performance. Our impression of the results is that sthe achievement of a better customer orientation performance occurs when the company is in training, and to benefit from its past knowledge and experience and also discovers new developing methods and stable relationships with the client.

\section{ACKNOWLEDGEMENTS}

This article has been extracted from Hamed Rostamian's MSc thesis, entitled "Investigate the Impact of Customer Relationship Management and Organizational Learning Capabilities on the Financial Performance of Producers of Herbal Products" done under the supervision of Dr Behrooz Hassanpour, visiting Professor of Yasouj Branch, Islamic Azad University (IAU). Thanks and appreciation to opinions of Professors of Department of Economics and Management, IAU of Yasouj, Iran.

\section{REFERENCES}

1. Keramati, A., Mehrabi, H., \& Mojir, N. (2010). A process-oriented perspective on customer relationship management and organizational performance: An empirical investigation. Industrial Marketing Management, 39(7), 1170-1185.

2. Hart, S., Hogg, G., \& Banerjee, M. (2004). Does the level of experience have an effect on CRM programs? Exploratory research findings, Industrial Marketing Management, 33: 549-560.

3. Khodakarami, F., \& Chand, Y. E. (2014). Exploring the role of customer relationship management (CRM) systems in customer knowledge creation, Information and Management, 51: 27-42.

4. Jayachandran, S., Sharma, S., Kaufman, P., \& Raman, P. (2005). The role of relational information processes and technology use in customer relationship management. Journal of marketing, 69(4), 177-192.

5. Chang, H. H., \& Ku, P. W. (2009). Implementation of relationship quality for CRM performance: Acquisition of BPR and organizational learning, Total Quality Management \& Business Excellence, 20(3): 327348.

6. Stein, A., \& Smith, M. (2009). CRM systems and organizational learning: An exploration of the relationship between CRM effectiveness and the customer information orientation of the firm in industrial markets. Industrial Marketing Management, 38(2): 198-206.

7. Garrido-Moreno, A., \& Padilla-Melendez, A. (2011). Analyzing the impact of knowledge management on CRM success: The mediating effects of organizational factors, International Journal of Information Management, 31: 437-444.

8. Ngai, E. W. (2005). Customer relationship management research (1992-2002) An academic literature review and classification. Marketing intelligence \& planning, 23(6), 582-605.

9. Mithas, S., Krishnan, M. S., \& Fornell, C. (2005). Dynamic Customer Relationship Management: Incorporating Future Considerations into the Service Retention Decision. Journal of Marketing, 69: 201-209.

10. Rapp, A., Trainor, K. J., \& Agnihotri, R. (2010). Performance implications of customer-linking capabilities: Examining the complementary role of customer orientation and CRM technology. Journal of Business research, 63(11), 1229-1236.

11. Cambra-Fierro, J., Florin, J., Perez, L., \& Whitelock, J. (2011). Inter-firm market orientation as antecedent of knowledge transfer, innovation and value creation in networks, Management Decision, 49(3): 444-467.

12. Peaen, M., Redrik, K., \& Malroony, C. (2005). Learning organizations in practice. [Trans.; A. Lamei]. Shahed \& Isargar publication. Uromia University of Medical Sciences.

13. Aghdasi, M., \& Befruei, M. K. (2009). Comparative Study of organizational learning capabilities as an organizational source of knowledge in public and private hospitals of Tehran: Nurses Perspectives. Iran journal of nursing, 21(56), 69-79.

14. Salehi, P., Sonboli, A., Eftekhar, F., NejadEbrahimi, S., \& Yousefzadi, M. (2005). Essential Oil Composition, Antibacterial and Antioxidant Activity of the Oil and Various Extracts of Ziziphora clinopodioides subsp. rigida (B OISS.) $\mathrm{R}$ ECH. f. from Iran. Biological and Pharmaceutical Bulletin, 28(10), 1892-1896.

15. Nguyen, T. H., Sherif, J. S., \& Newby, M. (2007). Strategies for successful CRM implementation. Information Management \& Computer Security, 15(2), 102-115.

16. Chen, I. J., \& Popovich, K. (2003). An empirical study the E-CRM performance influence model for service sectors in Taiwan, Business Process Management, 9(5): 672- 688.

17. Robbins, S. P. (1991). Organization behavior: concepts, controversies, and applications; prentice hall in international.

18. Britanica, Y. (1999). Leadership and organizational learning: A multiple levels perspective. The leadership quarterly, 17.

19. Valks, P. J. M., Piters, A. J. M., Lambert, J. C., Zehner, C., \& Kelder, H. (2003). A fast delivery system for the retrieval of near real-time ozone columns from GOME data. International Journal of Remote Sensing, 24(3), 423-436. 
20. Khalili, M. (2003). Learning organization: Necessity for change and development. Tadbir Journal, 137: 19.

21. Costanzo, L. A., \& Tzompa V. (2008). Enhancing organizational learning in teams: has the middle manager got a role? International Journal of Educational Management, 14(3-4): 146-164.

22. Mahammadi, M. (1998). Learning organizations are restored. Tadbir Journal, 90.

23. Arbab-Shirani, B. (2000). A Review of the Organizational Learning Literature Special Letter of the 8th Student Conference on Industrial Engineering, Azad University of Qazvin.

24. Kreitner, R., \& Angel, O. (2001). Organization behavior, Irwin, McGraw- Hill, Fifth edition. 1185

25. Hult, D., \& Ferrell, A. (1997). Learning in Action: A Guide to Putting the Learning Organization to Work. Boston: Harvard Business Press.

26. Kandemir, D., \& Hult, G. T. (2004). A conceptualization of an organizational learning culture in international joint ventures, Industrial Marketing Management, 34: 430-439.

27. Chu, S., DeRisi, J., Eisen, M., Mulholland, J., Botstein, D., Brown, P. O., \& Herskowitz, I. (1998). The transcriptional program of sporulation in budding yeast. Science, 282(5389), 699-705.

28. Schein, E. H. (1992). How can organizations learn faster? The problem of entering the Green Room.

29. Aydin, B., \& Ceylan, A. (2009). The effect of spiritual leadership on organizational learning capacity, African Journal of Business Management, 3(5): 184-190.

30. Al-mulali, U., Sab, C. N. B. C., \& Fereidouni, H. G. (2012). Exploring the bi-directional long run relationship between urbanization, energy consumption, and carbon dioxide emission. Energy, 46(1), 156-167.

31. Mohsinian-Brother's S. M., Khorakian, R., \& Maharati, Y. (2014). Investigating Customer Relationship Management on the Satisfaction of the Citizens of Municipality of Mashhad, Through the Role of Managerial Innovation in the Pattern of Iranian Islamic City. The 6th National Conference on Urban Planning and Management with emphasis on the components of Islamic city, Mashhad Islamic Council.

32. Montazer, S. N., Hoseini M. A., Yazdani, S. H., Nokhostin, M. R. (2015). Investigating the Status of Organizational Learning Capabilities and Obstacles and Facilitators at the University of Social Welfare and Rehabilitation Sciences, Medical Education Development Magazine, 8(7): 101-93.
33. Zablah, A. R., Bellenger, D. N., \& Johnston, W. J. (2004). Customer relationship management implementation gaps. Journal of Personal Selling \& Sales Management, 24(4), 279-295.

34. Lindgreen A., Palmer R., Vanhamme J., \& Wouters, J. (2006). A relationship management assessment tool: Questioning, identifying, and prioritizing critical aspects of customer relationships. Industrial Marketing Management, 35 (1): 57-71.

35. Soch, H., \& Sandhu, H. S. (2008). Does customer relationship management activity affect firm performance?. Global Business Review, 9(2), 189206.

36. Althonayan, M., \& Papazafeiropoulou, A. (2013, January). Evaluating the performance on ERP systems in King Saud University (KSU): A stakeholders' perspective. In 2013 46th Hawaii International Conference on System Sciences (pp. 4074-4083). IEEE.

37. BolíVar-Ramos, M. T., GarcíA-Morales, V. J., \& GarcíA-SáNchez, E. (2012). Technological distinctive competencies and organizational learning: Effects on organizational innovation to improve firm performance. Journal of Engineering and Technology Management, 29(3), 331-357.

38. Rashid, B. B., \& Tahir, S. B. (2013). Assessing the influence of customer relationship management (CRM) dimensions on organization performance: An emperical study in the hotel industry. Journal of Hospitality and Tourism Technology, 4(3), 228247.

39. Akgün, A. E., İmamoğlu, S. Z., Koçoğlu, İ., İnce, H., \& Keskin, H. (2014). Bridging organizational learning capability and firm performance through customer relationship management. ProcediaSocial and Behavioral Sciences, 150, 531-540.

40. Kalmuk, G., \& Acar, A. Z. (2015). Özel Hastanelerde Yenilikçilik ve Performans İlişkisinde Girişimciliğin Ara Değişken Etkisi. Hacettepe Sağllk İdaresi Dergisi, 21(4), 655-673.

41. Ghalenooie, M. B., \& Sarvestani, H. K. (2016). Evaluating human factors in customer relationship management case study: Private banks of shiraz city. Procedia Economics and Finance, 36, 363373.

42. Hair, J. F., Black, W., Babin, B. Y. A., Anderson, R., \& Tatham, R. (2010). RE [2010]: Multivariate Data Analysis. A Global Perspective.

43. Holand, S., Girard, A., Laude, D., Meyer-Bisch, C., \& Elghozi, J. L. (1999). Effects of an auditory startle stimulus on blood pressure and heart rate in humans. Journal of hypertension, 17(12), 18931897. 